International Journal of Engineering \& Technology, $7(3.18)(2018) 75-78$
International Journal of Engineering \& Technology
Website: www.sciencepubco.com/index.php/IJET
Technical paper

\title{
Effect of Spraying Parameters on the Morphology of Spray- Coated Active Layers for Organic Solar Cells
}

\author{
Nur Tahirah Razali ${ }^{1}$, Khairunisa Kamarudin ${ }^{1}$, Shusei Inaba ${ }^{2}$, Mahshuri Yusof ${ }^{1}$, Yeng Weng Leong $^{3}$ and Varun \\ Vohra ${ }^{2}$
}

\author{
${ }^{1}$ Faculty of Engineering, Universiti Malaysia Sarawak, 94300 Kota Samarahan, Sarawak, Malaysia \\ ${ }^{2}$ Department of Engineering Science, University of Electro-Communications, 1-5-1 Chofugaoka, Chofu, \\ Tokyo, 182-8585, Japan \\ ${ }^{3}$ Department of Electronics \& Communication Engineering, Universiti Tenaga Nasional, Malaysia \\ *Corresponding author E-mail: rntahirah@unimas.my
}

\begin{abstract}
Over the past decade, organic solar cells (OSCs) have demonstrated their great potential for the low-cost mass production of renewable energy. However, the conventional active layer deposition technique (spin-coating) is not suitable for mass production due to its incompatibility with the roll-to-roll process. Spray-coating is a promising candidate for in-line production of OSCs but parameters such as distance between the spray nozzle and substrate, applied pressure and number of sprays should be optimized to produce adequate film thickness and morphology. Here, we verified how these processing parameters influence the thin film properties and observed that film thickness increases with decreasing nozzle-substrate distance, increasing number of sprays or applied pressure. The processing parameters were adjusted to produce spray-coated films with similar properties to the spin-coated ones thus confirming that spray-coating could replace spin-coating for mass production of OSC devices.
\end{abstract}

Keywords: active layer; organic solar cells; P3HT; spray-coating; surface morphology.

\section{Introduction}

Due to increasing worldwide energy consumption, the demand for low-cost and large area photovoltaic modules production has been growing over the past decades. In fact, renewable energy can be produced at a low-cost through novel technologies such as organic solar cells (OSCs) which have a great potential for mass production using the roll-to-roll process. However, the conventional organic solution deposition method (spin-coating) is mostly suitable for lab-scale device fabrication. In fact, spin-coating not only generates a large amount of active material and solvent wastes but is also limited in terms of covered area and difficulties often arise when scaling-up the OSC fabrication process by spin-coating Consequently, recent studies have been focusing on developing and investigating alternative deposition processes adequate for mass production of large-scale modules. Among others, spraycoating, [1-5] slot-die coating,[6] gravure printing [7] and inkjet printing [8] have shown particularly encouraging results. When it comes to spray-coating, the coated solution properties (viscosity and used solvent) as well as the process parameters (spray nozzlesubstrate distance, number of sprays, pressure and spray speed rate) can greatly influence the quality of the produced films and consequently, the OSC device performances.[9] While OSC efficiencies and stability play an essential role for the potential commercialization of these new type of photovoltaic devices, a particular attention should also be given to reducing the use of chlorinated solvents which is harmful for both the human health and the environment.[10] Previous attempts to apply spray-coating to solar cell fabrication clearly demonstrate that similar performances to spin-coated films can be achieved while considerably decreasing the amount of wasted material. [11] Furthermore, past studies emphasize that the solvents used for the polymer layer deposition and the spraying time affect the surface morphology and thickness of the spray coated films.[1-3] Spray-coated films typically have a rougher surface as compared to the spin-coated ones.[4] Device performances may also be affected by blend ratio of donor acceptor materials and solution flow rates.[5] To further investigate the effect of spray parameters to the film thickness and morphology, in this study we spray-coated a poly(3-hexylthiophene-2,5-diyl) (P3HT): (6,6)-phenyl-C61-butyric acid methyl ester $\left(\mathrm{PC}_{61} \mathrm{BM}\right)$ solution by controlling the distance between the spray nozzle to the substrate, the applied pressure and the number of sprays. We compared the resulting morphologies with spin-coated film used as a reference and demonstrated that thin active layers which could be applied to OSC fabrication can be achieved by controlling the spray-coating parameters.

\section{Procedure and Experimental}

Glass substrates were cleaned using a standard cleaning procedure in acetone, deionized water and isopropanol. The substrates are then exposed to isopropanol vapor (heated at $200^{\circ} \mathrm{C}$ for $3 \mathrm{~min}$ ) to ensure that no residual solvent traces can be found on the substrate surfaces. The $\mathrm{P} 3 \mathrm{HT}$ and $\mathrm{PC}_{61} \mathrm{BM}$ were purchased from Rieke Materials and Luminescent Technology, respectively. The P3HT:PC61BM solution was prepared in $25: 20 \mathrm{mg} / \mathrm{ml}$ in chlorobenzene. After stirring for 4 hours at room temperature, the solution was spin-coated at $350 \mathrm{rpm}$ for $10 \mathrm{~s}$ followed by a planarization step at $700 \mathrm{rpm}$ for $50 \mathrm{~s}$ on top of clean glass substrates. Spray-coated films are produced using an airbrush where the 